\title{
Structure and Conformation of Protonated D-(+)-Biotin in the Unsolvated State
}

\author{
Caterina Fraschetti, ${ }^{\dagger}$ Antonello Filippi, ${ }^{\dagger}$ Laura Guarcini, ${ }^{\dagger}$ Vincent Steinmetz, ${ }^{\dagger}$ and Maurizio Speranza ${ }^{*}{ }^{\dagger}$ \\ †Dipartimento di Chimica e Tecnologie del Farmaco, Università "La Sapienza", Roma, Italy \\ ${ }^{*}$ Laboratoire Chimie Physique, UMR8000 CNRS, Université Paris Sud 11, Orsay, France
}

Supporting Information

ABSTRACT: A combined computational and infrared multiphoton dissociation (IRMPD) spectroscopic investigation shows that protonated D-(+)-biotin, formed in the gas phase by ESI-MS, acquires a folded structure with proton bonding between the ureido and valeryl carbonyls, and that only a single conformer of such a structure predominates. A uniform frequency vs distance correlation function is proposed for the $\mathrm{O}^{+}-\mathrm{H} \cdots \mathrm{O}$ and $\mathrm{N}-\mathrm{H} \cdots \mathrm{O}$ bonds involved in the folded conformers of $\mathrm{O}_{2}{ }^{\prime}$ protonated $\mathrm{D}-(+)$-biotin in the gas phase which, therefore, depends exclusively on the corresponding geometric parameters.

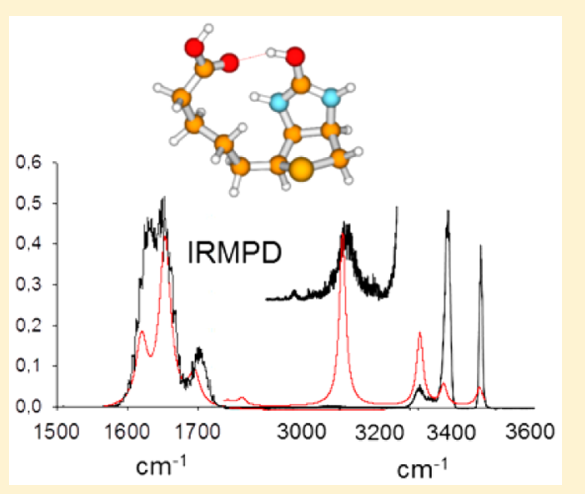

\section{INTRODUCTION}

$\mathrm{D}-(+)$-Biotin (Figure 1) is a water-soluble vitamin also called vitamin $\mathrm{H}$ or $\mathrm{B} 7$. It acts as a coenzyme in a number of enzymatic processes catalyzing the fixation and transfer of carbon dioxide. ${ }^{1,2}$ Reversible $\mathrm{D}-(+)$-biotin carboxylation proceeds through the selective substitution of the $1^{\prime}-\mathrm{NH}$ proton by the carboxylate group. ${ }^{3,4}$ Detailed NMR studies on the $\mathrm{NH}$ proton exchange rate in $\mathrm{D}-(+)$-biotin pointed out that the observed selectivity can be ascribed to the deactivation of the competing $3^{\prime}-\mathrm{NH}$ center due to intramolecular hydrogen bonding with the $\mathrm{COOH}$ group of the valeryl side chain. ${ }^{5-12}$ The $\mathrm{H}-\mathrm{D}$ exchange process is facilitated when temporary intramolecular proton transfer from the side chain carboxyl group to the ureido carbonyl group does not sterically interfere with the access to the $\mathrm{NH}$ groups. The $1^{\prime}-\mathrm{NH}$ group meets this steric condition, while the $3^{\prime}-\mathrm{NH}$ one does not.

The ureido ring of $\mathrm{D}-(+)$-biotin plays a crucial role in biochemistry since it strongly interacts with (strept)avidin to generate very stable noncovalent complexes suitable for biochemical sensing applications and for identifying new drug targets. ${ }^{13,14}$ Recently, D-(+)-biotin was also used as a cancertargeting ligand in most advanced theranostic drug delivery systems. ${ }^{15}$ Despite its key role, the structure and conformation of D-(+)-biotin is still a matter of debate. ${ }^{7-12,16,17} \mathrm{Ab}$ initio calculations indicate that the valeryl chain of $\mathrm{D}-(+)$-biotin can adopt, in the isolated state, either the extended or a folded form. ${ }^{8,10}$ The same happens in solution in spite of extensive solvation of all functional groups of the molecule. ${ }^{7,9}$ In crystal phase, only the extended structure is formed by virtue of intermolecular hydrogen bonding between two D-(+)-biotin molecules. ${ }^{16}$ Besides, no information is available yet as to the effects of protonation on the structure and conformation of $\mathrm{D}$ (+)-biotin. ${ }^{5,18}$

Gas-phase studies afford an opportunity to investigate the intrinsic properties of charged species in the "isolated state", not perturbed by solvent effects which are exceptionally difficult to probe experimentally. In the present investigation, the intrinsic structure and conformation of protonated $\mathrm{D}-(+)$-biotin is carried out from both the computational and spectroscopic standpoints. Experimental validation of the computational results is obtained by generating protonated $\mathrm{D}-(+)$-biotin in a mass spectrometer (MS) by electrospray ionization (ESI) and by assessing its structure and conformation by using variable wavelength IR multiphoton dissociation (IRMPD) spectroscopy. ${ }^{19-24}$

\section{MATERIALS AND METHODS}

IRMPD Experiments. D-(+)-Biotin was purchased from a commercial source and used without further purification. Protonated D-(+)-biotin was generated by ESI of calibrated solutions of $\mathrm{D}-(+)$-biotin $\left(10^{-5} \mathrm{M}\right)$ in pure $\mathrm{CH}_{3} \mathrm{OH}$. The ion was then introduced in a modified Bruker Esquire 6000 quadrupole ion trap and isolated using the standard Bruker Esquire Control (v6.2) software. ESI conditions used were as follows: syringe pump rate, $180 \mu \mathrm{L} \mathrm{h}^{-1}$; spray voltage, $3500 \mathrm{~V}$; capillary temperature, $250{ }^{\circ} \mathrm{C}$. Mass-selected ions were irradiated using the MS2 step, where the excitation amplitude was set to zero to avoid any collision-induced dissociation

Received: March 19, 2015

Revised: April 30, 2015

Published: May 4, 2015 


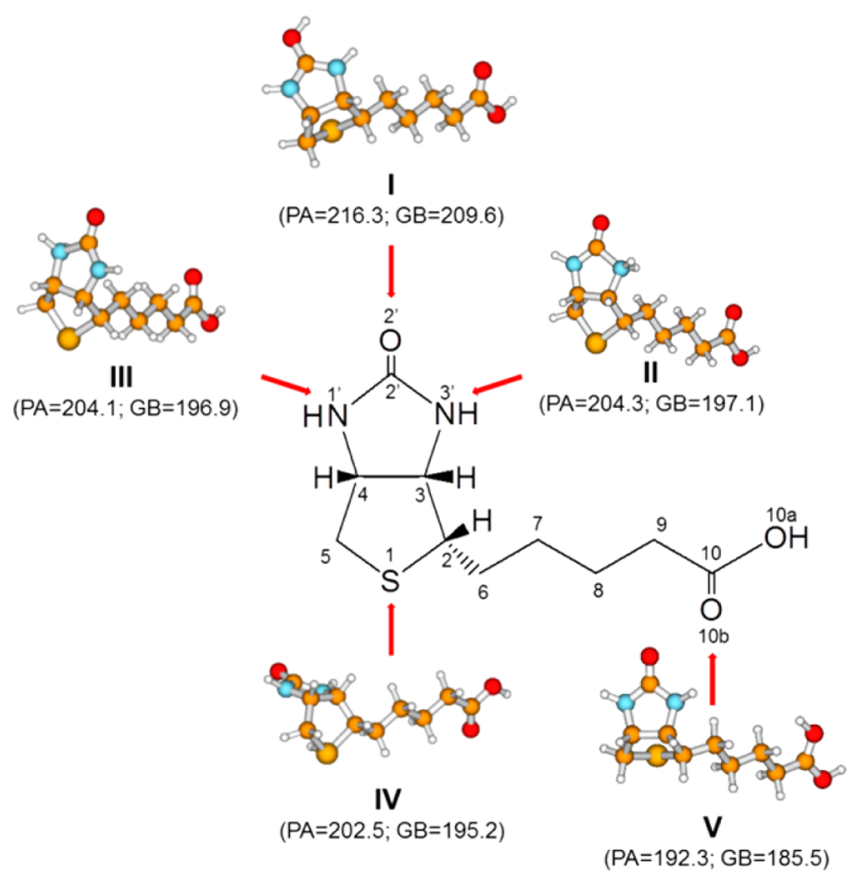

Figure 1. B3LYP/6-311++ $\mathrm{G}^{* *}$-optimized geometries of protonated D$(+)$-biotin in its extended form with the calculated PA's and GB's (kcal $\left.\mathrm{mol}^{-1}\right)$ of the most basic centers of extended D-(+)-biotin, i.e: $\mathrm{O}^{\prime}$ (structure I); N3' (structure II); N1' (structure III); S1 (structure IV); O10b (structure V). Prompt release of the $\mathrm{H}_{2} \mathrm{O} 10$ a molecule is observed during geometry optimization of the O10a-protonated D(+)-biotin.

(CID) process. The average of four mass spectra was recorded, using the $50-300 \mathrm{~m} / \mathrm{z}$ mass range and the $5500 \mathrm{~m} / \mathrm{z} \mathrm{s}^{-1}$ scan rate, the irradiation time being in the range of $200-500 \mathrm{~ms}$ in the FEL region and $2 \mathrm{~s}$ in the OPO/OPA one, depending on the fragmentation efficiency of the process. IR spectroscopy in the $900-2000 \mathrm{~cm}^{-1}$ wavenumber range was performed using the CLIO FEL. The light is produced in $8 \mu \mathrm{s}$ long pulse trains, the macropulses, of IR laser pulses a few picoseconds in duration, the micropulses. The repetition rate of the macropulses is $25 \mathrm{~Hz}$ while that of the micropulses is $62.5 \mathrm{MHz}$. Typical energies reached within one macropulse can be $40-60$ $\mathrm{mJ}$ : the macropulse energy in the present experiments is ca. 20 $\mathrm{mJ} .{ }^{25}$ The $2800-3800 \mathrm{~cm}^{-1}$ wavenumber range was explored using an IR optical parametric oscillator/amplifier (OPO/ OPA) system of LaserVision, pumped by a $10 \mathrm{~Hz}$ Nd:YAG laser (Excel Technology Europe GmbH Surelite-II, $650 \mathrm{~mJ}$ per pulse, 8 ns pulse duration). The output energy, measured between 3400 and $3600 \mathrm{~cm}^{-1}$, is ca. $23 \mathrm{~mJ}$ per pulse with a spectral bandwidth of ca. $5 \mathrm{~cm}^{-1}$. The loss of energy in the other spectral regions is not more than $14 \%$. The IR-FEL photon energy was increased at a rate of ca. $2.5 \mathrm{~cm}^{-1} \mathrm{~s}^{-1}$, while that from the OPO/OPA systems was increased at a rate of ca. $0.1 \mathrm{~cm}^{-1} \mathrm{~s}^{-1}$. In the IRMPD process, a photon is absorbed when the laser frequency matches a vibrational mode of the protonated $\mathrm{D}-(+)$-biotin $(m / z 245)$ and its energy is subsequently distributed over all vibrational modes of the ion by intramolecular vibrational redistribution (IVR). The IVR process allows the energy of each photon to be dissipated before the ion absorbs another, which leads to promotion of ion internal energy toward the dissociation threshold via multiple photon absorption. ${ }^{26}$ In agreement with CID experiments, IRMPD fragmentation of protonated D-(+)-biotin yields the $m / z 227$ fragment by formal loss of a water molecule. By recording the intensity of the parent $\mathrm{m} / z 245$ ion $\left(I_{\mathrm{P}}\right)$ and that of its $m / z 227$ fragment $\left(I_{\mathrm{F}}\right)$, while varying the frequency of the IR photons, the corresponding IRMPD spectrum is obtained. The IRMPD fragmentation efficiency is defined as $R$ $=-\log \left[I_{\mathrm{P}} /\left(I_{\mathrm{P}}+I_{\mathrm{F}}\right)\right] .{ }^{27}$ Infrared spectra obtained using IRMPD have been compared to those collected using linear absorption techniques. $^{28-30}$

Computational Details. Geometry optimization of the different isomers of protonated $\mathrm{D}-(+)$-biotin was achieved without any structural constraint at the B3LYP/6-311++G** level of theory, ${ }^{31-34}$ using the 1 MAY 2012 (R1) version of the general atomic and molecular electronic structure system (GAMESS) software. ${ }^{35,36}$ Harmonic vibrational frequencies were determined at this level to characterize the stationary points as local minima and to estimate their zero-point vibrational energy (ZPE) corrections as well as the relevant $298 \mathrm{~K}$ enthalpies and free energies. To correct calculated harmonic frequencies for the inherent vibrational anharmonicity, scaling factors were applied as recommended for the level of theory employed here, i.e., 0.98 for the frequencies in the $900-2000 \mathrm{~cm}^{-1}$ range and 0.96 for those in the $2800-3800$ $\mathrm{cm}^{-1}$ one. ${ }^{37,38}$

\section{RESULTS AND DISCUSSION}

Structure and Relative Stability of D-(+)-Biotin Protomers. Six different basic centers are present in D(+)-biotin, namely, the three oxygens, the two nitrogens, and the sulfur atom. In principle, six isomeric families of protonated $\mathrm{D}-(+)$-biotin can be generated, each including the $\mathrm{D}-(+)$-biotin side chain either in an extended or in a folded arrangement. ${ }^{8,10}$ In each of the six families, rotation around the five successive $\mathrm{C}-\mathrm{C}$ bonds in the valeryl chain would give rise to several hundreds of conformers. Therefore, to reduce the conceivable isomers of protonated $\mathrm{D}-(+)$-biotin to a manageable number, we first analyzed the relative stability of their extended forms as well as the relevant vibrational frequencies as compared to the IRMPD spectrum of ESI-formed protonated D-(+)-biotin. Figure 1 reports the $\mathrm{B} 3 \mathrm{LYP} / 6-311++\mathrm{G}^{* *}$-optimized geometries of protonated $\mathrm{D}-(+)$-biotin in its extended form and the calculated proton affinity (PA) and gas-phase basicity (GB) of its basic centers at the same level of theory. As shown in the figure, the most basic site of the extended form of $\mathrm{D}-(+)$-biotin is the $\mathrm{O}^{\prime}$ atom (structure I). Both N3' (structure II) and $\mathrm{N1}^{\prime}$ centers (structure III), as well as the $\mathrm{S} 1$ one (structure IV), are over $10 \mathrm{kcal} \mathrm{mol}^{-1}$ less basic than $\mathrm{O}^{\prime}$. Protonation of the $\mathrm{O} 10 \mathrm{~b}$ is even less favored (structure $\mathbf{V}$ ), whereas that at the O10a center leads to the prompt release of the $\mathrm{H}_{2} \mathrm{O} 10 \mathrm{a}$ molecule.

The most significant absorption frequencies of the extended protomers $\mathbf{I}-\mathbf{V}$ falling in the $1500-2000 \mathrm{~cm}^{-1}$ range are listed in Table 1 , together with the predominant IRMPD signals of protonated $\mathrm{D}-(+)$-biotin observed within the same frequency range (vide infra). The same comparison, but extended to the fingerprint region, is given in Figures S1-S5 of the Supporting Information section as well. From their comparison it results that the IRMPD signals are more consistent with the absorption frequencies of the extended isomer of $\mathrm{O}_{2}^{\prime}$ protonated $\mathrm{D}-(+)$-biotin I calculated at the B3LYP/6-311+ $+\mathrm{G}^{* *}$ level of theory.

This conclusion is further supported by fact that no IRMPD signals are attributable to the $\mathrm{C}^{\prime}=\mathrm{O} 2^{\prime}$ stretching frequency of the other protomers II-V (Table 1 and Figures S1-S5 of the 
Table 1. B3LYP/6-311++G**-Calculated Frequencies of the Extended Structures I-V of Protonated D-(+)-Biotin (See Figure 1)

\begin{tabular}{|c|c|c|c|}
\hline protomer & & $\begin{array}{l}\mathrm{C} 10=\mathrm{O} 10 \\
\text { stretching }\end{array}$ & $\begin{array}{l}\mathrm{C} 2^{\prime}=\mathrm{O} 2^{\prime} \\
\text { stretching }\end{array}$ \\
\hline I & $\begin{array}{l}1618\left(\mathrm{C} 2^{\prime}-\mathrm{N} 3^{\prime}\right. \\
\text { stretching })\end{array}$ & 1779 & 1670 \\
\hline II & $\begin{array}{l}1599\left(\mathrm{H}-\mathrm{N} 3^{\prime}-\mathrm{H}\right. \\
\text { scissoring) }\end{array}$ & 1778 & 1924 \\
\hline III & $\begin{array}{l}1607\left(\mathrm{H}-\mathrm{N1}^{\prime}-\mathrm{H}\right. \\
\text { scissoring })\end{array}$ & 1777 & 1926 \\
\hline IV & $\begin{array}{l}1400\left(\mathrm{C} 2^{\prime}-\mathrm{N} 3^{\prime}\right. \\
\text { stretching })\end{array}$ & 1781 & 1827 \\
\hline $\mathbf{V}$ & $\begin{array}{l}1406\left(\mathrm{C}^{\prime}-\mathrm{N} 3^{\prime}\right. \\
\text { stretching })\end{array}$ & 1516,1588 & 1786 \\
\hline $\begin{array}{l}\text { ESI- } \\
\text { IRMPD }\end{array}$ & 1632 & 1706 & 1649 \\
\hline
\end{tabular}

Supporting Information) as well as to the calculated absorption frequencies of their most stable folded isomers (Figures S6S10 of the Supporting Information). On these grounds, the discussion is henceforth focused on the conformational analysis of ESI-formed O2'-protonated D-(+)-biotin.

Conformation of the $\mathrm{O}^{\prime}$-Protonated $\mathrm{D}-(+)$-Biotin. Figure 2 illustrates the $\mathrm{B} 3 \mathrm{LYP} / 6-311++\mathrm{G}^{* *}$-calculated structure and stability of the most stable folded conformers of $\mathrm{O}^{\prime}$ protonated $\mathrm{D}-(+)$-biotin relative to the extended form $\mathrm{I}$. The positive $\Delta H=H_{\mathrm{I}}-H_{\mathrm{F}}$ and $\Delta G=G_{\mathrm{I}}-G_{\mathrm{F}}$ values in Figure 2 indicate that the corresponding folded structures $\mathbf{F}$ are more

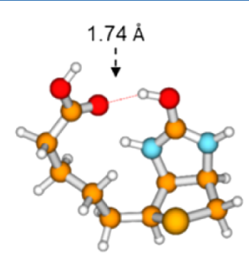

g- $\mathbf{A}_{a} \quad\left(\gamma=74^{\circ}\right)$

$\Delta H=13.2 \mathrm{kcal} \mathrm{mol}^{-1}$ $\Delta G=9.9 \mathrm{kcal} \mathrm{mol}^{-1}$

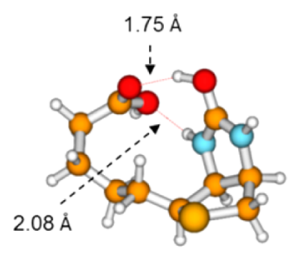

${ }^{g+} \mathbf{A}_{s} \quad\left(\gamma=286^{\circ}\right)$

$\Delta H=2.9 \mathrm{kcal} \mathrm{mol}^{-1}$ $\Delta G=-0.6 \mathrm{kcal} \mathrm{mol}^{-1}$

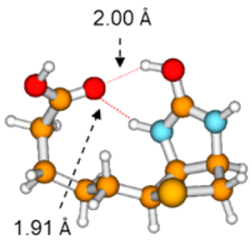

${ }^{g+} \mathbf{A}_{a} \quad\left(\gamma=297^{\circ}\right)$

$\Delta H=11.2 \mathrm{kcal} \mathrm{mol}^{-1}$ $\Delta G=8.3 \mathrm{kcal} \mathrm{mol}^{-1}$

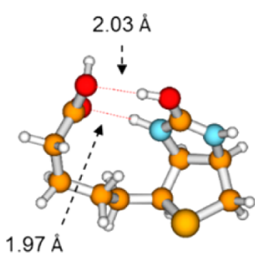

g- $\mathbf{B}_{\boldsymbol{s}} \quad\left(\gamma=86^{\circ}\right)$

$\Delta H=0.9 \mathrm{kcal} \mathrm{mol}^{-1}$

$\Delta G=-2.1 \mathrm{kcal} \mathrm{mol}^{-1}$

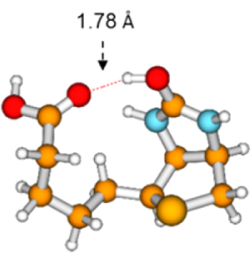

${ }^{t} \mathbf{A}_{\mathbf{S}} \quad\left(\gamma=153^{\circ}\right)$

$\Delta H=5.5 \mathrm{kcal} \mathrm{mol}^{-1}$ $\Delta G=2.4 \mathrm{kcal} \mathrm{mol}^{-1}$

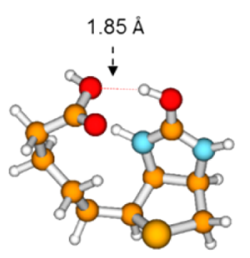

${ }^{g} \cdot \mathbf{B}_{\mathbf{a}} \quad\left(\gamma=77^{\circ}\right)$

$\Delta H=-1.2 \mathrm{kcal} \mathrm{mol}^{-1}$ $\Delta G=-3.8 \mathrm{kcal} \mathrm{mol}^{-1}$

Figure 2. B3LYP/6-311++G**-calculated structure and stability of the folded conformers of $\mathrm{O}_{2}$-protonated $\mathrm{D}-(+)$-biotin relative to the extended form I. The capital letter refers to the specific proton bonding: A $\left(\mathrm{O}^{\prime}-\mathrm{H}^{+} \ldots \mathrm{O} 10 \mathrm{~b}\right)$; B $\left(\mathrm{O}^{\prime}-\mathrm{H}^{+} \ldots \mathrm{O} 10 \mathrm{a}\right)$. The superscript of the capital letter refers to the torsional angle $\gamma=\mathrm{C} 7-\mathrm{C} 6-\mathrm{C} 2-\mathrm{C} 3$ $\left(\gamma=240-360^{\circ}\left(\right.\right.$ gauche $\left.^{+}\right), 120-240^{\circ}$ (trans-anti), and $0-120^{\circ}$ $\left(\right.$ gauche $\left.^{-}\right)$); the $a$ subscript (anti) indicates that the $\mathrm{O} 10 \mathrm{a}-\mathrm{H}$ bond in the $\mathbf{A}$ conformers (the $\mathrm{O} 10 \mathrm{~b}$ atom in the $\mathbf{B}$ conformers) is oriented away from the bridgehead hydrogens; the $\boldsymbol{s}$ subscript (syn) indicates that the $\mathrm{O} 10 \mathrm{a}-\mathrm{H}$ bond in the $\mathbf{A}$ conformers (the O10b atom in the $\mathbf{B}$ conformers) is oriented toward the bridgehead hydrogens. $\Delta H=H_{\mathrm{I}}-$ $H_{\mathrm{F}} ; \Delta G=G_{\mathrm{I}}-G_{\mathrm{F}}$ (the subscript $\mathbf{F}$ denotes a folded structure and the subscript $\mathbf{I}$ the extended one $\mathbf{I})$. stable than the extended one $\mathrm{I}$. Side chain folding in conformers ${ }^{g-} \mathbf{A}_{a}{ }^{g+} \mathbf{A}_{a}$ and ${ }^{t} \mathbf{A}_{s}$ (the used symbolism is explained in the Figure 2 caption) produces the most significant stability gains, whereas the effect is almost negligible or even adverse in conformers ${ }^{g+} \mathbf{A}_{s},{ }^{g-} \mathbf{B}_{s}$, and ${ }^{g-} \mathbf{B}_{a}$. Such a different outcome is attributable to the effect of the torsional strain of the valeryl side chain on the nature and the strength of the intramolecular interactions between the remote $\mathrm{COOH}$ group and the $\mathrm{O}_{2}^{\prime}-\mathrm{H}^{+}$ center of D-(+)-biotin (cf. A and $\mathbf{B}$ families of Figure 2).

For instance, the $\gamma=\mathrm{C} 7-\mathrm{C} 6-\mathrm{C} 2-\mathrm{C} 3=74^{\circ}$ dihedral angle in ${ }^{{ }^{-}-} \mathbf{A}_{a}$ allows the establishment of an intense $\mathrm{O} 2^{\prime} \mathrm{H}^{+} \ldots \mathrm{O} 10 \mathrm{~b}$ proton bond ( $1.74 \AA$ ). A further $223^{\circ}$ torsion of angle $\gamma$ leads to a significant weakening of the same interaction in conformer ${ }^{g+} \mathbf{A}_{a}(2.00 \AA)$, partially compensated by the establishment of the $\mathrm{N} 3^{\prime} \mathrm{H} \cdots \mathrm{O} 10 \mathrm{~b}$ hydrogen bond (1.91 $\AA$ ). Moreover, the syn or anti orientation of $\mathrm{COOH}$ group may play some role as well. Thus, the weak $\mathrm{O} 2{ }^{\prime} \mathrm{H}^{+} \ldots \mathrm{O} 10 \mathrm{~b}$ interaction in ${ }^{g^{+}} \mathbf{A}_{a}(2.00 \AA)$ becomes rather strong in the ${ }^{g^{+}} \mathbf{A}_{s}$ conformer (1.75 $\AA$ ). Finally, it should be noted that the opposite effect is observed for the strength of the $\mathrm{O}_{2}{ }^{\prime} \mathrm{H}^{+} \ldots \mathrm{O} 10 \mathrm{a}$ bond, as shown by comparing the proton bond distances in ${ }^{g-} \mathbf{B}_{a}$ and ${ }^{g-} \mathbf{B}_{s}$.

Also the $\mathrm{C} 10=\mathrm{O} 10 \mathrm{~b}$ stretching frequency of the conformers of Figure 2 is affected by the proton interaction with the $\mathrm{O}_{2}^{\prime} \mathrm{H}^{+}$ center as shown by the black arrows in Figure 3a. Relative to the $\mathrm{C} 10=\mathrm{O} 10 \mathrm{~b}$ stretching frequency at $1779 \mathrm{~cm}^{-1}$ of the extended structure $\mathbf{I}$, significant red shifts are observed for the folded conformers, as in ${ }^{g-} \mathbf{A}_{a},{ }^{g+} \mathbf{A}_{a}$, and ${ }^{t} \mathbf{A}_{s}$, characterized by the $\mathrm{O} 2^{\prime} \mathrm{H}^{+} \ldots \mathrm{O} 10 \mathrm{~b}$ interaction. In contrast, those showing the $\mathrm{O} 2^{\prime} \mathrm{H}^{+} \ldots$ O10a bonding, i.e., ${ }^{g-} \mathbf{B}_{s}$ and ${ }^{g-} \mathbf{B}_{a}$, exhibit a blue shift. This can be explained by the fact that a partial positive charge on a carbonyl oxygen decreases the electron density of the double bond, while the opposite effect takes place when a partial positive charge is placed on the carbonyl carbon atom.

As shown in Figure 3a, the 1500-2000 cm $\mathrm{cm}^{-1}$ IRMPD spectrum of the ESI-formed protonated D- $(+)$-biotin is in good agreement with the calculated absorption spectra of the most stable conformers ${ }^{g-} \mathbf{A}_{a}{ }^{g+} \mathbf{A}_{a}$ and ${ }^{t} \mathbf{A}_{s}$ (for a comparison within the $900-1500 \mathrm{~cm}^{-1}$ region, see Figures $S 11$ and $S 12$ of the Supporting Information). Discrimination among these conformers may take advantage of the fact that the vibrational stretch of the $\mathrm{O}^{\prime}-\mathrm{H}^{+}$bond is rather sensitive to the $\mathrm{O} 2^{\prime}-$ $\mathrm{H}^{+} \ldots \mathrm{O} 10 \mathrm{~b}$ interaction, whose strength is mediated by the torsional strain of the side chain (Figure 2). The result is illustrated in Figure 3b, which compares the B3LYP/6-311+ $+\mathrm{G}^{* *}$-calculated vibrational spectra of the conformers of Figure 2 with the 2900-3700 $\mathrm{cm}^{-1}$ IRMPD spectrum of the ESIformed protonated $\mathrm{D}-(+)$-biotin. Within this frequency range, the spectrum of protonated $\mathrm{D}-(+)$-biotin is characterized by the presence of five signals at 3562, 3475, 3405, 3180, and 2960 $\mathrm{cm}^{-1}$, whose relative intensity does not match that calculated for the conformers of Figure 2. In this connection, it should be considered that an ion structure can be detected in IRMPD experiments only if it can absorb enough photoenergy to allow unimolecular dissociation of the ion into the products. If ion dissociation involves the breaking of a strong covalent bond, e.g., the $\mathrm{C}-\mathrm{O}$ bond of protonated $\mathrm{D}-(+)$-biotin to form the leaving water molecule, the ion must absorb several IR photons, depending on their energy. ${ }^{39}$ Thus, it may happen that the resonant multiphoton absorption by a given IR-active vibrational mode may produce a weak signal, although calculations, based on pure absorption phenomena, predict a much stronger one (Figure 3b). 


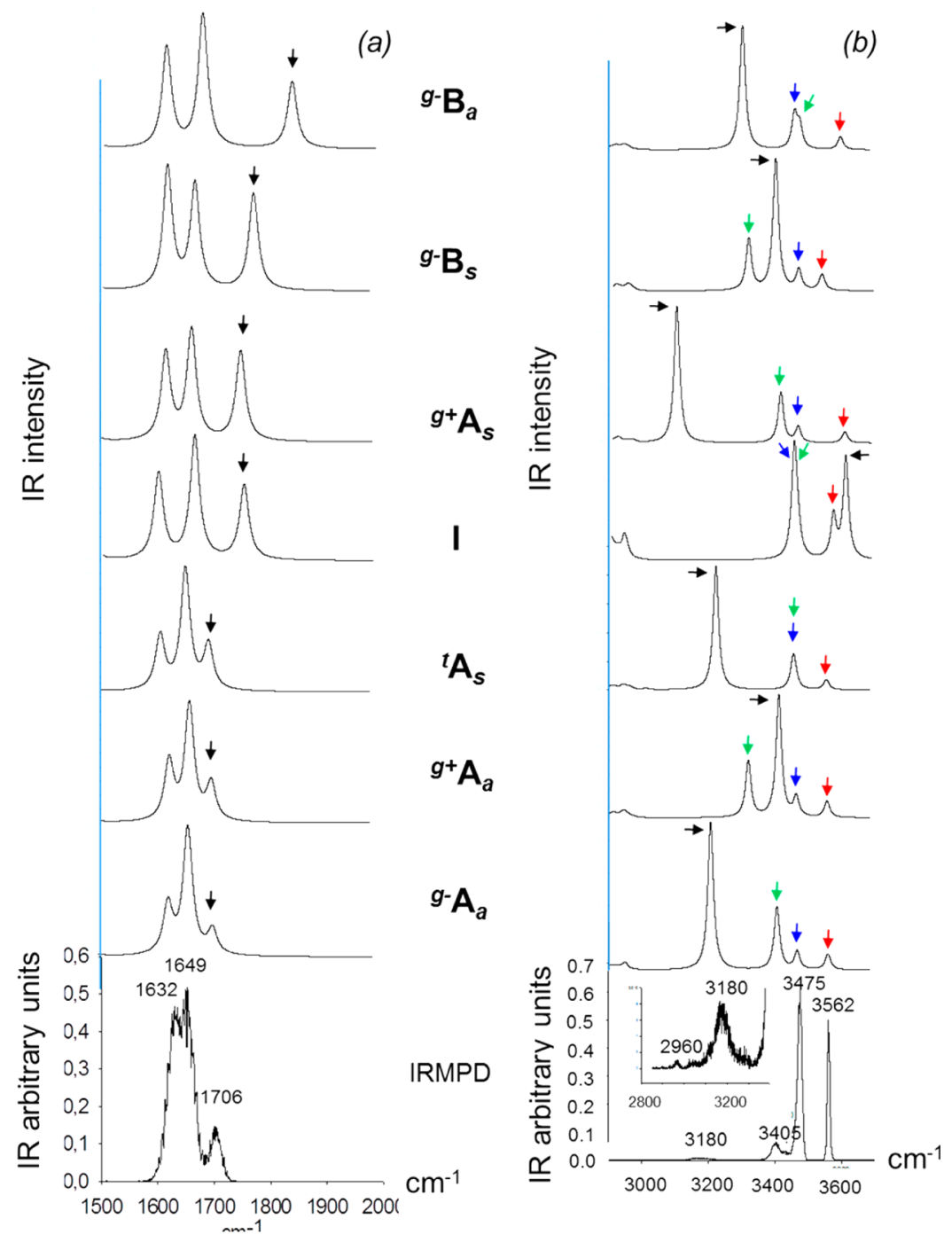

Figure 3. Comparison between the IRMPD spectra of ESI-formed protonated D-(+)-biotin and the B3LYP/6-311++G**-calculated absorption frequencies of the stable structures of Figure 2 taken in the $1500-2000 \mathrm{~cm}^{-1}$ (a) and $2900-3700 \mathrm{~cm}^{-1}$ (b) frequency ranges. Bond stretching frequencies: (a) $\mathrm{C} 10=\mathrm{O} 10 \mathrm{~b}$ (black arrows); (b) $\mathrm{O}^{\prime+}-\mathrm{H}$ (black arrows); $\mathrm{O} 10 \mathrm{a}-\mathrm{H}$ (red arrows); $\mathrm{N} 1-\mathrm{H}$ (blue arrows); $\mathrm{N} 3-\mathrm{H}$ (green arrows). The calculated adsorption spectra were constructed using Molden 4.7 (G. Schaftenaar and J. H. Noordik, J. Comput.-Aided Mol. Des. 2000, 14, 123134) program, by selecting " 10 " as the width parameter.

The B3LYP/6-311++ $\mathrm{G}^{* *}$-calculated frequencies of the stretching vibrations of the folded conformers ${ }^{g-} \mathbf{A}_{a},{ }^{g+} \mathbf{A}_{a}$, and ${ }^{t} \mathrm{~A}_{s}$ are indicated in Figure $3 \mathrm{~b}$ by the colored arrows: $\mathrm{O} 2^{\prime+}-\mathrm{H}$ (black); O10a-H (red); $\mathrm{N}^{\prime}-\mathrm{H}$ (blue); $\mathrm{N}^{\prime}-\mathrm{H}$ (green). As shown in the figure, the $\mathrm{O} 10 \mathrm{a}-\mathrm{H}$ and $\mathrm{N} 1^{\prime}-\mathrm{H}$ stretching frequencies are rather insensitive to the structural features, while the $\mathrm{O} 2^{\prime+}-\mathrm{H}$ (black) and $\mathrm{N} 3^{\prime}-\mathrm{H}$ (green) ones are dramatically affected by the nature and the strength of their intramolecular interactions with the valeryl oxygens, determined in turn by the specific conformation. In particular, relative to the free $\mathrm{O}_{2}{ }^{+}-\mathrm{H}$ stretching frequency of the extended protomer I, significant red shifts $\left(\geq 200 \mathrm{~cm}^{-1}\right)$ are observed for all the folded conformers of Figure 2, in particular those exhibiting the strongest proton bonds, i.e., ${ }^{g-} \mathbf{A}_{a}(1.74 \AA)$, ${ }^{t} \mathbf{A}_{s}(1.78 \AA)$, and ${ }^{g+} \mathbf{A}_{s}(1.75 \AA)$. In the same way, relative to the free $\mathrm{N}-\mathrm{H}$ stretching frequencies of the extended protomer $\mathbf{I}$, red shifts around $100 \mathrm{~cm}^{-1}$ are observed for the folded conformers of Figure 2 characterized by significant N $3^{\prime}-\mathrm{H} \cdots$ O10b interactions, i.e., ${ }^{g+} \mathbf{A}_{a}(1.91 \AA)$ and ${ }^{g-} \mathbf{B}_{s}(1.97 \AA)$.
The relationship between the calculated stretching frequencies $\nu(\mathrm{X}-\mathrm{H})\left(\mathrm{X}=\mathrm{O}_{2}{ }^{\prime}, \mathrm{N} 3^{\prime}\right)$ of the stable conformers of Figure 2 and the corresponding hydrogen bond distances $r(\mathrm{X}-$ $\mathrm{H} \cdots \mathrm{Y})$ is illustrated in Figure 4. Frequency $(\nu(\mathrm{X}-\mathrm{H}))$ vs $\mathrm{H}$ bond distance $(r(\mathrm{X}-\mathrm{H} \cdots \mathrm{Y}))$ correlation curves, as that shown in the figure, have been established for various kinds of hydrogen bonds in the condensed phase. ${ }^{40-43}$

A substantial fraction of the observed red shift and signal broadening of the $\mathrm{X}-\mathrm{H}$ stretching band has been attributed to an increase of anharmonicity of the potential energy surface along the stretching coordinate. Several equations, such as eq 1 , have been proposed for the $\nu(\mathrm{X}-\mathrm{H})$ vs $\mathrm{r}(\mathrm{X}-\mathrm{H} \cdots \mathrm{Y})$ correlations where $\nu(\mathrm{X}-\mathrm{H})_{\text {free }}$ is the frequency of the free $\mathrm{X}-\mathrm{H}$ bond, $\chi_{\mathrm{Y}}=3.65$ is the electronegativity of the acceptor $\mathrm{Y}$, $r_{\mathrm{X}}+r_{\mathrm{Y}}$ is the hydrogen bond contact radius $(=2.84 \AA$ in the present case), and $a$ and $b$ are two Y-dependent regression parameters. 


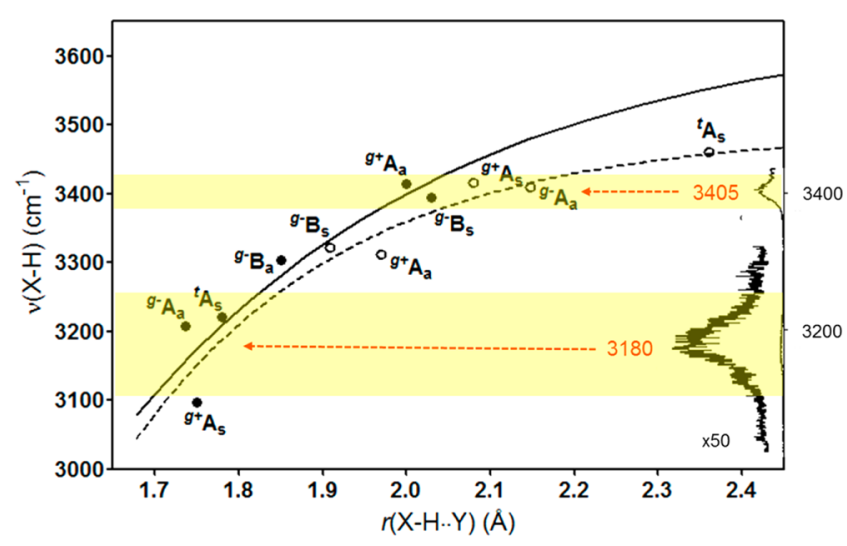

Figure 4. Correlation curves between the calculated stretching frequencies $\nu(\mathrm{X}-\mathrm{H})\left(\mathrm{X}=\mathrm{O}^{\prime+}\right.$ (full symbols; solid line; $r^{2}=0.947$; $\mathrm{X}=\mathrm{N} 3^{\prime}$ (open symbols; broken line; $\left.r^{2}=0.930\right)$ ) of the stable conformers of Figure 2 and the corresponding hydrogen bond distances $(r(\mathrm{X}-\mathrm{H} \cdots \mathrm{Y}))$. The inset refers to the diagnostic IRMPD signals of ${ }^{{ }^{-}} \mathbf{A}_{a}$ between 3000 and $3430 \mathrm{~cm}^{-1}$ (Figure $3 \mathrm{~b}$ ).

$$
\begin{aligned}
\nu(\mathrm{X}-\mathrm{H})= & \nu(\mathrm{X}-\mathrm{H})_{\text {free }} \\
& -a \exp \left[b \chi_{\mathrm{Y}}\left(r_{\mathrm{X}}+r_{\mathrm{Y}}-r(\mathrm{X}-\mathrm{H} \cdots \mathrm{Y})\right)\right]
\end{aligned}
$$

Best fitting the solid symbols of Figure $4\left(r^{2}=0.947\right)$, using eq 1 , yields $\nu(\mathrm{X}-\mathrm{H})_{\text {free }}=3664 \mathrm{~cm}^{-1}$, a value which compares well with the $\mathrm{O}_{2}^{\prime+}-\mathrm{H}$ stretching frequency in the extended structure I $\left(3637 \mathrm{~cm}^{-1}\right)$, together with $a=33.04$ and $b=0.68$. Best fit of the open symbols $\left(r^{2}=0.930\right)$ yields $\nu(\mathrm{X}-\mathrm{H})_{\text {free }}=$ $3492 \mathrm{~cm}^{-1}$, a value which closely matches the $\mathrm{N}-\mathrm{H}$ stretching frequencies in the extended structure I (symm, $3490 \mathrm{~cm}^{-1}$; asymm, $\left.3479 \mathrm{~cm}^{-1}\right)$, together with $a=5.72$ and $b=1.02$. Despite the significant differences between the $\nu\left(\mathrm{O} 2^{\prime+}-\mathrm{H}\right)_{\text {free }}$ and $\nu(\mathrm{N}-\mathrm{H})_{\text {free }}$ values arising from the best fitting procedure, the corresponding values in the proton- and hydrogen-bonded structures $(1.8 \AA<(r(\mathrm{X}-\mathrm{H} \cdots \mathrm{Y})<2.2 \AA$; Figure 4$)$ could be approximately described by a single correlation curve pointing to a convergent effect of the acceptor $\mathrm{Y}$ (in the present case one of the side chain $\mathrm{COOH}$ oxygens) on both the $\mathrm{O}^{+}-\mathrm{H}$ and $\mathrm{N}-$ $\mathrm{H}$-bond stretchings in the $\mathrm{X}-\mathrm{H} \cdots \mathrm{Y}\left(\mathrm{X}=\mathrm{O}^{+}, \mathrm{N}\right)$ interactions. Besides, it indicates that, in the gas phase, in the absence of the fluctuating environment interactions with the solvent, the red shift of the $\mathrm{X}-\mathrm{H}$ stretching band depends exclusively on the $\mathrm{X}-\mathrm{H} \cdots \mathrm{Y}$ geometric parameters. ${ }^{43}$

It is concluded that the diagnostic signatures at $1706 \mathrm{~cm}^{-1}$ (Figure 3a) as well as at 3180 and $3405 \mathrm{~cm}^{-1}$ (Figure $3 \mathrm{~b}$ and the inset of Figure 4), recorded in the IRMPD spectrum of protonated $\mathrm{D}-(+)$-biotin, are only compatible with the $\mathrm{C}^{\prime}=$ $\mathrm{O} 2^{\prime}, \mathrm{N} 3^{\prime}-\mathrm{H} \cdots \mathrm{O} 10 \mathrm{~b}$, and $\mathrm{O}^{\prime+}-\mathrm{H} \cdots \mathrm{O} 10 \mathrm{~b}$ stretching frequencies of the most stable conformer ${ }^{g-} \mathbf{A}_{a}$ which, therefore, is predominantly generated under ESI-MS conditions.

\section{ASSOCIATED CONTENT}

\section{S Supporting Information}

Comparison between the IRMPD signals of ESI-formed protonated $\mathrm{D}-(+)$-biotin and the B3LYP/6-311++G**-calculated absorption frequencies of the isomeric forms. The Supporting Information is available free of charge on the ACS Publications website at DOI: 10.1021/acs.jpcb.5b02660.

\section{AUTHOR INFORMATION}

\section{Corresponding Author}

*E-mail: maurizio.speranza@uniroma1.it. Tel: +39-06 49913497.

\section{Notes}

The authors declare no competing financial interest.

\section{ACKNOWLEDGMENTS}

Work supported by the Ministero dell'Istruzione dell'Università e della Ricerca (PRIN 2010-2011: CUP B81J1200283001, prot. 2010ERFKXL_006). CLIO's staff in Orsay and Annito Di Marzio in Rome are gratefully acknowledged for their technical support.

\section{REFERENCES}

(1) Adina-Zada, A.; Zeczycki, T. N.; St. Maurice, M.; Jitrapakdee, S.; Cleland, W. W.; Attwood, P. V. Allosteric regulation of the biotindependent enzyme pyruvate carboxylase by acetyl-CoA. Biochem. Soc. Trans. 2012, 40, 567-572.

(2) Adina-Zada, A.; Zeczycki, T. N.; Attwood, P. V. Regulation of the structure and activity of pyruvate carboxylase by acetyl CoA. Arch. Biochem. Biophys. 2012, 519, 118-130.

(3) Jitrapakdee, S.; St. Maurice, M.; Rayment, I.; Cleland, W. W.; Wallace, J. C.; Attwood, P. V. Structure, mechanism and regulation of pyruvate carboxylase. Biochem. J. 2008, 413, 369-387.

(4) Attwood, P. V.; Wallace, J. C. Chemical and Catalytic Mechanisms of Carboxyl Transfer Reactions in Biotin-Dependent Enzymes. Acc. Chem. Res. 2002, 35, 113-120.

(5) Perrin, C. L.; Dwyer, T. J. Proton exchange in biotin: a reinvestigation, with implications for the mechanism of carbon dioxide transfer. J. Am. Chem. Soc. 1987, 109, 5163-5167.

(6) Cravey, M. J.; Kohn, H. Model studies on the mechanism of biotin-dependent carboxylations. 2. Site of protonation vs. carbon dioxide transfer. J. Am. Chem. Soc. 1980, 102, 3928-3939.

(7) Tonan, K.; Adachi, K.; Ikawa, S. NMR study of selective H-D exchange of amide protons of D-biotin with deuterium oxide in dimethyl sulfoxide. Spectrochim. Acta, Part A 1998, 54, 989-997.

(8) Strzelczyk, A. A.; Dobrowolski, J. Cz.; Mazurek, A. P. On the conformation of the biotin molecule. J. Mol. Struct. (THEOCHEM) 2001, 541, 283-290.

(9) Zhang, R.; Lei, Y.; Li, H. Why 1-NH and 3-NH Protons of DBiotin Exhibit Different Activities in Aqueous Solution. J. Phys. Chem. B 2008, 112, 8779-8782.

(10) Zhang, L.; Li, H.; Hu, X.; Han, S. 1-NH proton of biotin is not always more active than 3-NH proton. Chem. Phys. Lett. 2006, 421, 334-337.

(11) Grasel, J. A. A nuclear magnetic resonance investigation of biotin. The biotin sulfonium ion. Biochemistry 1966, 5, 1851-1855.

(12) Fry, D. C.; Fox, T. L.; Lane, M. D.; Mildvan, A. S. Exchange characteristics of the amide protons of d-biotin and derivatives: implications for the mechanism of biotin enzymes and the role of sulfur in biotin. J. Am. Chem. Soc. 1985, 107, 7659-7665.

(13) Bykhovski, A.; Zhang, W.; Jensen, J.; Woolard, D. Analysis of Electronic Structure, Binding, and Vibrations in Biotin-Streptavidin Complexes Based on Density Functional Theory and Molecular Mechanics. J. Phys. Chem. B 2013, 117, 25-37 and references therein.

(14) Deng, L.; Broom, A.; Kitova, E. N.; Richards, M. R.; Blake Zheng, R.; Shoemaker, G. K.; Meiering, E. M.; Klassen, J. S. Kinetic Stability of the Streptavidin-Biotin Interaction Enhanced in the Gas Phase. J. Am. Chem. Soc. 2012, 134, 16586-16596.

(15) Maiti, S.; Park, N.; Han, J. H.; Jeon, H. M.; Lee, J. H.; Bhuniya, S.; Kang, C.; Kim, J. S. Gemcitabine-Coumarin-Biotin Conjugates: A Target Specific Theranostic Anticancer Prodrug. J. Am. Chem. Soc. 2013, 135, 4567-4572 and references therein.

(16) DeTitta, G. T.; Blessing, R. H.; Moss, G. R.; King, H. F.; Sukumaran, D. K.; Roskwitaski, R. L. Inherent Conformation of the 
Biotin Bicyclic Moiety: Searching for a Role for Sulfur. J. Am. Chem. Soc. 1994, 116, 6485-6493.

(17) Valadbeigi, Y.; Farrokhpour, H.; Tabrizchi, M. DFT study on the isomerization and tautomerism in vitamins B3 (niacin), B5 (pantothenic acid) and B7 (biotin). Chem. Phys. Lett. 2014, 601, 155162.

(18) Caplow, M. Biotin basicity. Biochemistry 1969, 8, 2656-2658.

(19) Roithova, J. Characterization of reaction intermediates by ion spectroscopy. Chem. Soc. Rev. 2012, 41, 547-559.

(20) Polfer, N. C. Infrared multiple photon dissociation spectroscopy of trapped ions. Chem. Soc. Rev. 2011, 40, 2211-2221.

(21) Eyler, J. R. Infrared multiple photon dissociation spectroscopy of ions in Penning traps. Mass Spectrom. Rev. 2009, 28, 448-467.

(22) Brodbelt, J. S.; Wilson, J. J. Infrared multiphoton dissociation in quadrupole ion traps. Mass Spectrom. Rev. 2009, 28, 390-424.

(23) MacAleese, L.; Maitre, P. Infrared spectroscopy of organometallic ions in the gas phase: from model to real world complexes. Mass Spectrom. Rev. 2007, 26, 583-605.

(24) Fung, Y. M. E.; Besson, T.; Lemaire, J.; Maitre, P.; Zubarev, R. A. Room-Temperature Infrared Spectroscopy Combined with Mass Spectrometry Distinguishes Gas-Phase Protein Isomers. Angew. Chem., Int. Ed. 2009, 48, 8340-8342.

(25) Mac Aleese, L.; Simon, A.; McMahon, T. B.; Ortega, J. M.; Scuderi, D.; Lemaire, J.; Maitre, P. Mid-IR spectroscopy of protonated leucine methyl ester performed with an FTICR or a Paul type ion-trap. Int. J. Mass Spectrom. 2006, 249-250, 14-20.

(26) Bagratashvili, V. N.; Letokov, V. A.; Makarov, A. A.; Ryabov, E. A. Multiple Photon Infrared Laser Photophysics and Photochemistry; Harwood: Chur, Switzerland, 1985.

(27) Lemaire, J.; Boissel, P.; Heninger, M.; Mauclaire, G.; Bellec, G.; Mestdagh, H.; Simon, A.; Caer, S. L.; Ortega, J. M.; Glotin, F.; Maitre, P. Gas Phase Infrared Spectroscopy of Selectively Prepared Ions. Phys. Rev. Lett. 2002, 89, 273002/1-273002/4.

(28) Moore, D. T.; Oomens, J.; Eyler, J. R.; von Helden, G.; Meijer, G.; Dunbar, R. C. Infrared Spectroscopy of Gas-Phase Cr+ Coordination Complexes: Determination of Binding Sites and Electronic States. J. Am. Chem. Soc. 2005, 127, 7243-7254.

(29) Oomens, J.; Tielens, A. G. G. M.; Sartakov, B. G.; von Helden, G.; Meijer, G. Laboratory Infrared Spectroscopy of Cationic Polycyclic Aromatic Hydrocarbon Molecules. Astrophys. J. 2003, 591, 968-985.

(30) van Stipdonk, M. J.; Basu, P.; Dille, S. A.; Gibson, J. K.; Berden, G.; Oomens, J. Infrared Multiple Photon Dissociation Spectroscopy of a Gas-Phase Oxo-Molybdenum Complex with 1,2-Dithiolene Ligands. J. Phys. Chem. A 2014, 118, 5407-5418.

(31) Becke, A. D. Density-functional exchange-energy approximation with correct asymptotic behavior. Phys. Rev. A 1988, 38, 3098-3100.

(32) Becke, A. D. A new mixing of Hartree-Fock and local-densityfunctional theories. J. Chem. Phys. 1993, 98, 1372-1377.

(33) Becke, A. D. Density-functional thermochemistry. IV. A new dynamic correlation functional and implications for exact-exchange mixing. J. Chem. Phys. 1996, 104, 1040-1046.

(34) Lee, C.; Yang, W.; Parr, R. G. Development of the Colle-Salvetti correlation-energy formula into a functional of the electron density. Phys. Rev. B 1988, 37, 785-789.

(35) Schmidt, M. W.; Baldridge, K. K.; Boatz, J. A.; Elbert, S. T.; Gordon, M. S.; Jensen, J. H.; Koseki, S.; Matsunaga, N.; Nguyen, K. A.; Su, S. J.; Windus, T. L.; Dupuis, M.; Montgomery, J. A. General atomic and molecular electronic structure system. J. Comput. Chem. 1993, 14, $1347-1363$.

(36) Gordon, M. S., Schmidt, M. W. In Theory and Applications of Computational Chemistry: the first forty years; Dykstra, C. E., Frenking, G., Kim, K. S., Scuseria, G. E., Eds.; Elsevier: Amsterdam, 2005; pp 1167-1189.

(37) Andersen, M. P.; Uvdal, P. New Scale Factors for Harmonic Vibrational Frequencies Using the B3LYP Density Functional Method with the Triple- $\zeta$ Basis Set 6-311+G(d,p). J. Phys. Chem. A 2005, 109, 2937-2941.

(38) Bakker, J. M.; Redlich, B.; van der Meer, A. F. G.; Oomens, J. Infrared spectroscopy of gas-phase polycyclic aromatic hydrocarbon cations in the $10-50 \mu \mathrm{m}$ spectral range. Astrophys. J. 2011, 741, 74/1$74 / 9$.

(39) Oomens, J.; Sarkatov, B. G.; Meijer, G.; von Helden, G. Gasphase infrared multiple photon dissociation spectroscopy of massselected molecular ions. Int. J. Mass Spectrom. 2006, 254, 1-19.

(40) Novak, A. Hydrogen bonding in solids. Correlation of spectroscopic and crystallographic data. Struct. Bonding (Berlin, Ger.) 1974, 18, 177-216.

(41) Mikenda, W. Stretching frequency versus bond distance correlation of $\mathrm{O}-\mathrm{D}(\mathrm{H}) \ldots \mathrm{Y}(\mathrm{Y}=\mathrm{N}, \mathrm{O}, \mathrm{S}, \mathrm{Se}, \mathrm{Cl}, \mathrm{Br}, \mathrm{I})$ hydrogen bonds in solid hydrates. J. Mol. Struct. 1986, 147, 1-15.

(42) Mikenda, W.; Steinböck, S. Stretching frequency vs bond distance correlation of hydrogen bonds in solid hydrates: a generalized correlation function. J. Mol. Struct. 1996, 384, 159-163.

(43) Nibbering, E. T. J.; Elsaesser, T. Ultrafast Vibrational Dynamics of Hydrogen Bonds in the Condensed Phase. Chem. Rev. 2004, 104, 1887-1914. 